\title{
SCADA Implementations to Supervise the Water Networks Infrastructures in the City of Athens
}

\author{
M. Papoutsidakis \\ Dept. of Industrial Design \\ and Production \\ Engineering \\ University of West Attica, \\ Athens, Greece
}

\author{
E. Theocharis \\ Dept. of Industrial Design \\ and Production \\ Engineering \\ University of West Attica, \\ Athens, Greece
}

\author{
D. Piromalis \\ Dept. of Industrial Design \\ and Production \\ Engineering \\ University of West Attica, \\ Athens, Greece
}

\author{
A. Sort \\ Dept. of Industrial Design \\ and Production \\ Engineering \\ University of West Attica, \\ Athens, Greece
}

\begin{abstract}
The aim of this research work, is to report on the interface between a SCADA system and the user of that system. The paper also aims to describe how a SCADA system helps people supervise and control electromechanical installations. The electromechanical installations of the water supply network of Athens city, are also described in this project. There is also a description of some devices, who play a vital role in the operation of the installations and the telemetry that takes place via SCADA. Examples of such devices are PLC, inverter, measuring devices and more. Lastly, SCADA systems are reported on, in a general point of view and in a more specific one, this of the handling of a water supply network.
\end{abstract}

\section{Keywords}

Supervisory systems, scada implementations, water network control, flow control

\section{INTRODUCTION}

This project aims to report on the importance of remote supervision in a water supply network. Remote supervision is used in supervision of electromechanical installations in water supply networks, remotely through SCADA. Remote supervision of installations offers important benefits in time, resources, reliability etc. The ability of remote supervision and control is of great importance in a water supply network. Through remote supervision, we assure the proper function, optimised customer service and the best possible quality of our product, water.

Besides remote supervision, the field this diploma is about is water supply networks and specifically the network of Athens Water Supply and Sewerage Company (EYDAP) . A water supply network is a composite system that consists of water distribution pipelines and a large number of parts. [1].

From a more general point of view the EYDAP network consists of pipelines and installations. Pipelines deliver the treated water. Pipelines guide water from Water Treatment Units to the measurers of customers. From the term installation we most of it refer to pump stations (simple or thrust) and tanks. These installations help supplying water to areas that it would be impossible through natural flow, due to their high attitude. So EYDAP's network includes 81 pump stations and 55 tanks with a capacity of $8885000 \mathrm{~m} 3$, that are scattered in points who locate in high altitude. The water supplied areas by EYDAP may have altitude between 0-600 meters over sea level. The network is divided in sections for a better performance, as we can see in the next picture. In picture E.1 we can see three sections but they are actually four, as there is further division at the three main sections of the picture. Most of the data and examples that this diploma contains, come from Athens section. This section has red colour on the next picture. It extends from Galatsi to Sounio. [2].

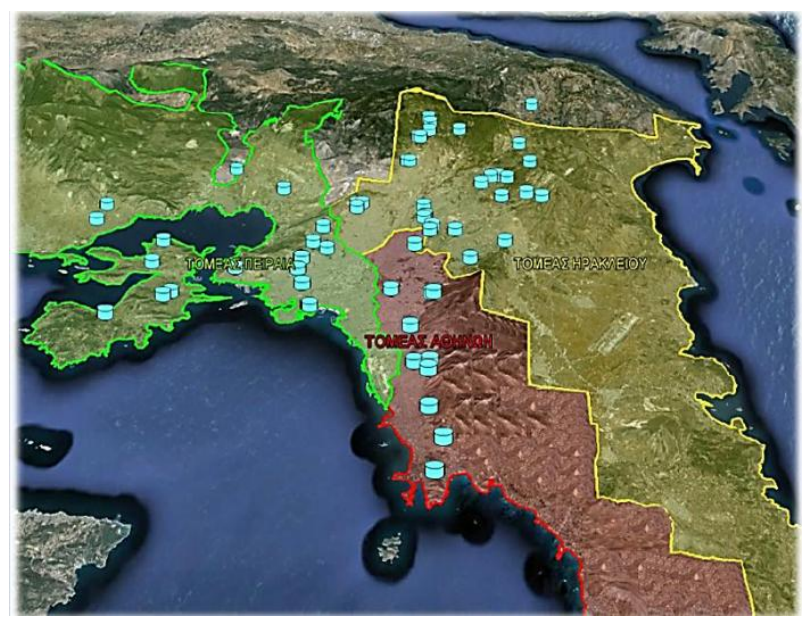

Fig 1: Tank map per section. [2].

The water supply network is supervised $24 / 7$ by SCADA system, that offers the abilities of remote operating and controlling. This system has 100 check points that are located inside the network, for supervising its overall function [3].

\section{ELECTROMECHANICAL INSTALLATIONS}

A water supply network consists of projects of external aqueduct and distribution networks. In this project we will deal exclusively with distribution networks and more specifically with the electromechanical (EM) installations they contain. A water supply network usually includes three types of EM installations. These are: Pumping station, tank, booster.

The term electromechanical is derived from the fact that knowledge of the field of electrical engineering and / or mechanical engineering, is required to handle the basic machinery and components associated with an EM installation.

\section{PUMPING STATION}

Pumping stations are used when there is a need to transfer liquid from one location to another, while the two locations differ in some of their characteristics. These characteristics are pressure and / or altitude. With regard to pressure, fluid is transported from a room with lower pressure to another with 
higher. In respect of the altitude, the fluid is usually transported from lower to higher. [9].

In the water supply network of EYDAP, a pumping station may supply other pumping stations or tanks, which supply areas that are located at high altitude. Or it may supply the network directly. [1].

The pumping station project is carried out using pumps. These pumps work together. The number of pumps in each pump station as well as their power is calculated on the basis of the needs to be met by the pumping station. There is always at least one spare pump, that is used in case of a breakdown or in case of a very heavy workload.

\section{WATER TANK}

A tank is a very important part of water supply networks. It performs three basic functions, which are the following. [4]:

1. Regulates the inflow 24/7. Upstream, the flow is constant throughout the day. In downstream parts of the network, the supply depends on fluctuations of the demand throughout the day. [4].

2. Adjusts the downstream pressure on the network. [4].

3. Stores water that can be used in case of emergency. Such a case may be some damage to the aqueduct or a fire. [4].

A water tank can of course be understood as an electromechanical installation. In addition to chambers and pipes, inside a tank there are machines and components, as they exist inside a pumping station or a booster. In a water supply network there are tanks and tanks / pumping stations. In the second category, a tank is located in the same space with a pumping station.

\section{BOOSTER}

Boosters are used in the water supply network to avoid flowing water circulation problems. Such problems may appear due to low pressure values. In many areas of the city, there is a significant altitude difference between the tank and residential areas or various facilities that need to be supplied with water. There may also be a great distance between them. Therefore, there is not enough pressure for the naturally flowing water to reach the consumers. In these cases, a booster is inserted to increase the water pressure.

A booster is an underwater complex for pumping. Each booster is a horizontal arrangement in which a pump is coaxially connected to a motor. [18]. They are also known as thrust pumping stations, and their operation is very similar to that of simple pumping stations.

\section{PUMPING STATION'S AUTOMATION PANEL}

Pumping station's automation panels are used to connect the pumps of a pumping station (simple or thrust) with the PLCs. Their role is to transfer control signals and operating signals between the PLC and the pumps. Also through the automation panels, the control type of the system is switched according to the needs (remote control, automatic, local, manual). [20].

\section{PLC}

Most electromechanical installations are equipped with PLC. PLC have a vital role for the execution of various automations in an installation. Technicians execute an operation scenario case in PLC. According to the scenario, pumps start and stop automatically and alarms are sent to the monitoring center etc. Of course PLC is connected to the wider network of SCADA system. This connection is possible through digital and analogical inputs and outputs of PLC (DI, DO, AI, AO). Through SCADA cooperation with PLC, user can get a full image of an EM installation current status. He can also intervene when considered necessary, in situations as the following:

A PLC's D.I is connected to the hardware that detects alarms which are under the category "entrance in the installation". If there is a digital signal of logical 1 in this D.I. ,PLC will communicate with SCADA and will send an alarm signal. The technicians will be informed and act accordingly.

In an electromechanical installation, there are also analogical signals. The three basic sensors used in EM installations, measure continuously changing quantities. These three are the manometer (pressure), flowmeter (water flow), water level meter (water tank level). The measurements performed by these sensors end up in A.I of PLC. Low pressure, flow or level measures, might indicate the start of pump operation and the opposite. Due to PLC-SCADA connection, the quantities changes, are sent to the monitoring system.

\section{INDUCTIVE MOTOR WITH SHORT CIRCUITED ROTOR}

The asynchronous three-phase motor is the type of motor that is most commonly used in industry. Reasons fort his, is low sale cost as well as low maintenance cost, its simple construction and big concentration in force. It is also named inductive motor. It was named like this because of the inductive motors stimulation current, that is not guaranteed by any source, but is created by induction.[8]. Therefore there is no separate stimulation circuit. In the inductive motor, currents and voltages are inducted in its stimulation and thus this reminds us the operation principle of an adaptor. [24].

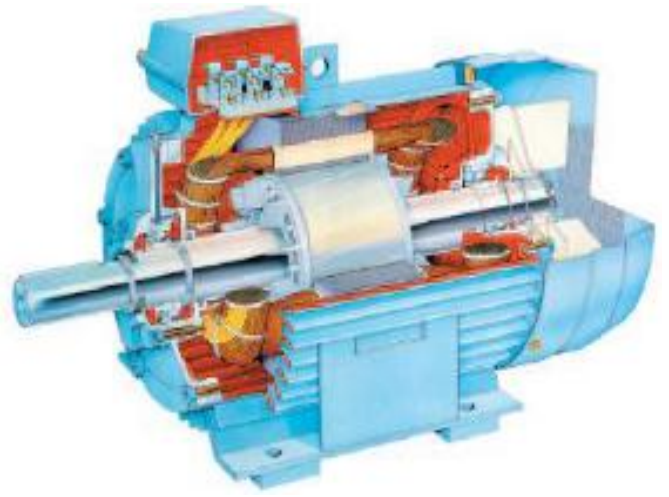

Fig 2: Inductive motor with short circuited rotor. [8].

\section{INVERTER}

The core of Electromechanical installations in the water supply network, are pumps. The main part of a pump is the asynchronous three phase motor with short-circuited rotor. For the proper operation of an installation, it is necessary to check the rotation of most of motors. The best way to check the rotation of motors is by using inverter. Inverters provide us with a clear idea for the status of sizes, which are of great importance for the right operation of the system. These might be operating frequency, current, pump pressure etc. Inverter provides us also with information related to various operation errors which appear in an installation. All the above mentioned information provided by inverter, are accessible to personnel through SCADA system. In the system there is also 
a data base with history of errors, statistics for the operation of motors etc.

\section{SCADA SYSTEMS}

The term SCADA is an abbreviation of the words Supervisory Control and Data Acquisition. SCADA systems is basically an application of the science of industrial informatics. This application, helps us to supervise a production process as well as other processes. [29].

All these processes whether or not related to the production of products, they are characterized by a set of basic parameters. These parameters are very important for the operation of the system in which the process is a part of, as well as for its control. For example, in the water supply network, the basic parameters are the pressure of the flowing water, its supply/flow from and to various facilities or the network, and water tanks levels.

SCADA systems focus in the basic parameters of the process. More particularly, these parameters are monitored online on a 24-hour basis by PLC and their values are recorded. In that way, a clear image of their status is provided at all times. Also through mimic diagrams and more generally through HMI, SCADA systems represent the process as a whole or its individual pieces in a plausible way. Finally, they notify about any problematic situations and offer great potential in the field of remote control of the various installations.

HMI terms is an abbreviation of the words Human Machine Interface. It is an instrument that presents the user with process data and situations. Through this HMI, the operator can supervise the process and intervene in the various functions it involves. HMI is a mean for interaction between SCADA system and human factor. Through the computer monitor it gives the necessary information to the user in a graphic manner. It actually uses mimic diagrams and therefore provides a visual representation of the process as a whole, but also of each function and components separately. HMI provides access to diagrams, variable values and component status. [29].

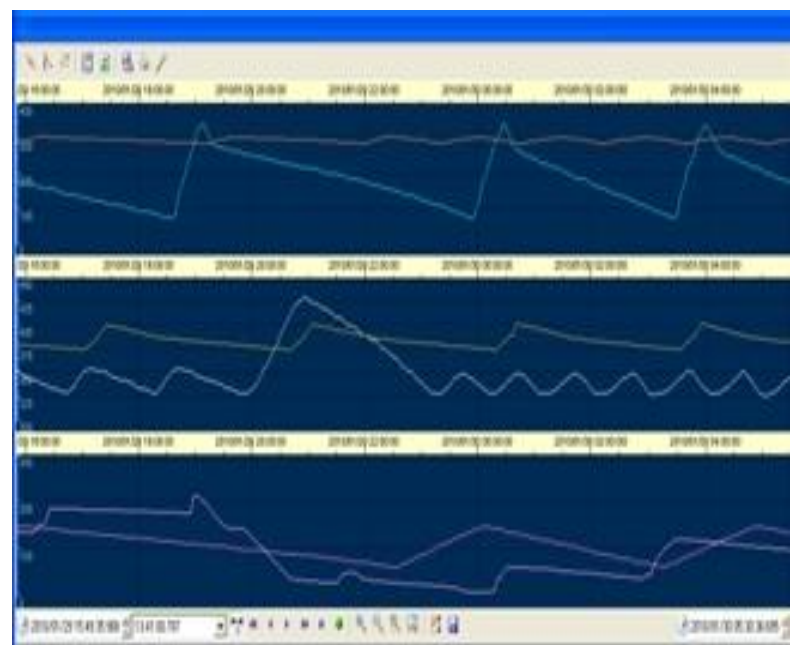

Fig 3: Water level of tanks and water chlorination. [32].

A SCADA is consisted of monitoring center, communication lines -networks, RTU and the system that it controls. [29].

Regarding RTU, telemetry can be understood as sending measurement and control signals between two RTUs, or sending them to and from multiple RTUs. One of the main characteristics of SCADA as a term, is that it refers to remote control. RTU are the elements that embody the concept of remote control as they are installed in locations considered remote and their function is to send and receive signals and data. RTU communicates with the central PC of SCADA system. [31].

\section{SUPPLY NETWORK MANAGEMENT}

A SCADA system is a part of a set, aiming at the proper function of a water supply network. In order for a water supply network to operate properly, proper management is considered necessary. Before this, the network must be recorded. For the two functions above, basic tools are G.I.S and the mathematical simulation of the water supply network

\section{SCADA SYSTEMS IN THE WATER SUPPLY NETWORK MANAGEMENT}

In order to create the remote control-telemetry system that we manage through SCADA, communication between the following stations is required:

1. Central Control Station (CCS): It is also referred to as a control center and is usually located at the headquarters of the respective company or sector. It includes the software and hardware required to collect and manage data, perform remote control and general management of the system. [36].

2. Regional Control Stations (RCS): They are located at the premises of the company or sector, which of course follow the CCS in a hierarchy. In the case we study, the RCS is the central crew of the EM installations, which is the base of the technicians. Their mission is to collect data, remotely manage and monitor a water supply network in general. They work in close collaboration with the CCS.

3. Local stations: They are placed in network control positions, which means in all electromechanical installations. By installing the local stations in the EM installations, logically we have the possibility of local control and remote control. [36].

A remote control network is made up of external and local networks. External networks are used to connect local stations with the CCS, some stations between them, and finally, make connections between external networks. Local networks operate at local stations. They are used to connect the RTU communication node in a local station with the PLCs, sensors and various instruments and devices. This node is connected to external networks. [37].

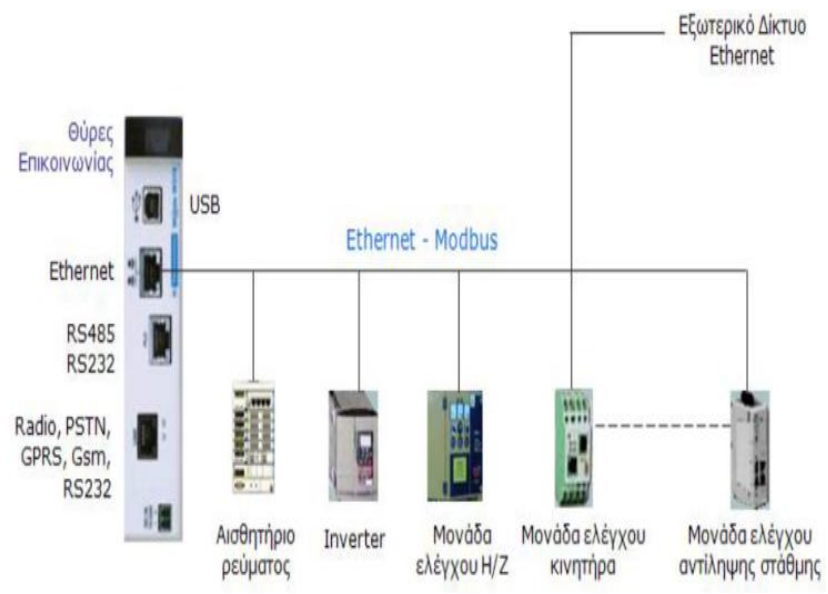

Fig 4: Local network Ethernet-Modbus. [37] 


\section{SCADA IN THE NETWORK OF EYDAP, ATHENS SECTON}

The user communicates with the program through the computer located in the technicians base, i.e. the RCS. The status of the water supply network is depicted on the computer screen via mimic diagrams, graphs, price lists, hydraulicmechanical drawings. The computer screen displays all the information gathered from the several check points. All of this information may involve values of physical sizes, machine operating states, various alarms as well as communication issues. Indicative information that can be obtained from the system is the following: communication failure, sensor or instrument failure, pump operation or non-operation, various alarms like floor water, entrance to the station, etc.

The user has access to the general design of an installation or group of installations. He can thus see the location of an installation within the network and understand which facility directly affects another.

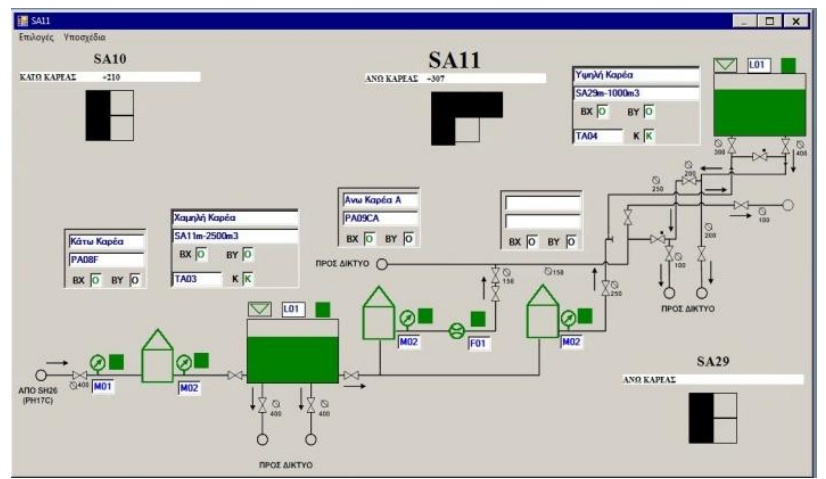

Fig 5: General design of a group of installations. [28].

Some information is also available on each facility in particular. E.g. data regarding pumps of a pumping station and design for their layout.

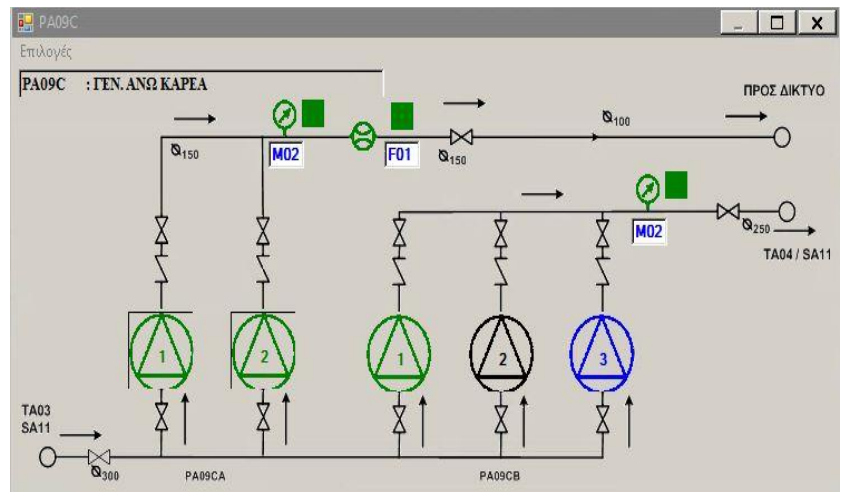

Fig 6: The inside of a pumping station. [28].

There is an incident window that that depicts all of the installations. The coloring of the piece that corresponds to each installation is of great importance.

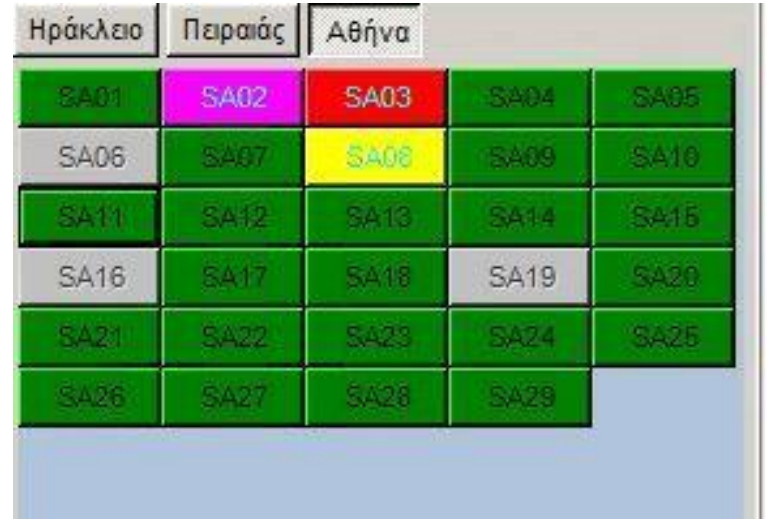

Fig 7: Incident window. Three incidents in the Athens section at the moment the screenshot was taken . [28].

1. Green color: All right.

2. Red: There is a problem associated with an instrument or some other alarm that is not part of any category. An instrument may be damaged, or alarming values ( alarmingly high or low) of the measured size may arrive at the program. With regard to alarms that do not fit into any category, red coloring is possible to occur in cases such as water on the floor, or damage to electrical components.

3. Yellow: Entrance to the room of an installation.

4. Purple: Communication failure. The program has stopped receiving values from this stationinstallation. It is also likely to receive values, but they arrive late.

The above colors are also shown in the symbol that is included in a design and corresponds to a specific installation .Additionally, an installation or component may have a blue or black color on the general design, or on a design that shows the inside of an installation.

5. Blue: Stand mode.

6. Black: Out of order.

SCADA also provides some alarm tables These tables give us details about the various alarms-incidents occurring in an installation, or overall in the section.

\begin{tabular}{|c|c|c|c|}
\hline Huвроипvía & Etränós & Kwöikós Opyávou & Періурасі́ \\
\hline 16:042018 08:43:05 & SA29 & SA29 & floter 1 NAl \\
\hline 16/042018 04:51:43 & SA11 & SA11 & floter $1 \mathrm{NAl}$ \\
\hline $17022201807: 30: 34$ & SA12 & TA05_MO3 & 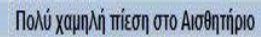 \\
\hline 130712017 13:42:33 & SAOG & SAOG & B'áßB Emikonwvias \\
\hline 130712017 13:42:33 & SA16 & SA16 & Bגáßn Emikorwuvias \\
\hline 13:07/2017 13:42:33 & SA19 & SA19 & 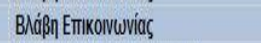 \\
\hline $05103201413: 54: 58$ & SA19 & TA11 & 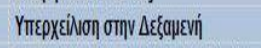 \\
\hline $0203201406: 07: 33$ & SA19 & TA11_L01 & 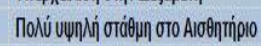 \\
\hline
\end{tabular}

Fig 8: Alarm table. [28].

In the example above, the alarms and facts presented are as follows: Flotter 1 has reached its limit, very low pressure on the sensor, communication failure, overflow in the tank, very high level in the sensor.

Information is also provided on: The time and date of occurrence of the fact, the station concerned, the instrument concerned. 
The most important measuring instruments (sensors) used in the network are the following:<smiles></smiles>
[28] : manometer

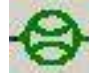
[28] : water level meter.

[28 ]: flowmeter,

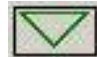

With the help of these instruments, SCADA provides an overview of pressure, water flow and water level in the network. By means of graphs, we can observe the procession of a size in the temporal range we are interested in.

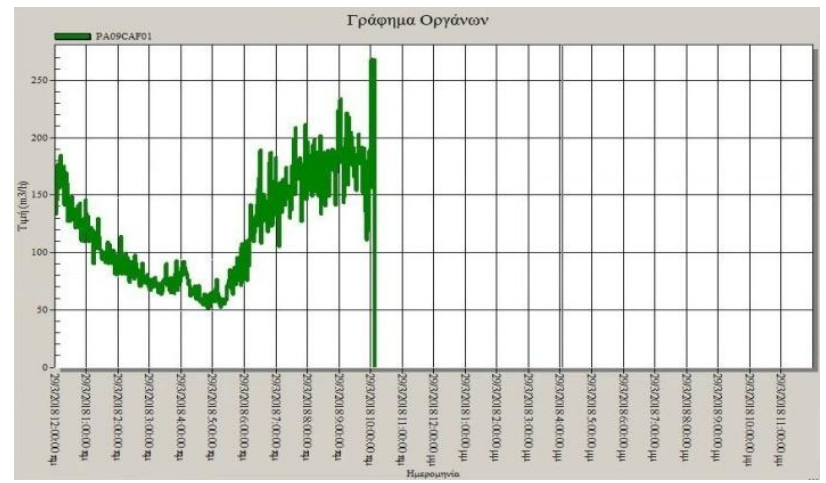

Fig 9:.Flowmeter graph, temporal range: this day. [28].

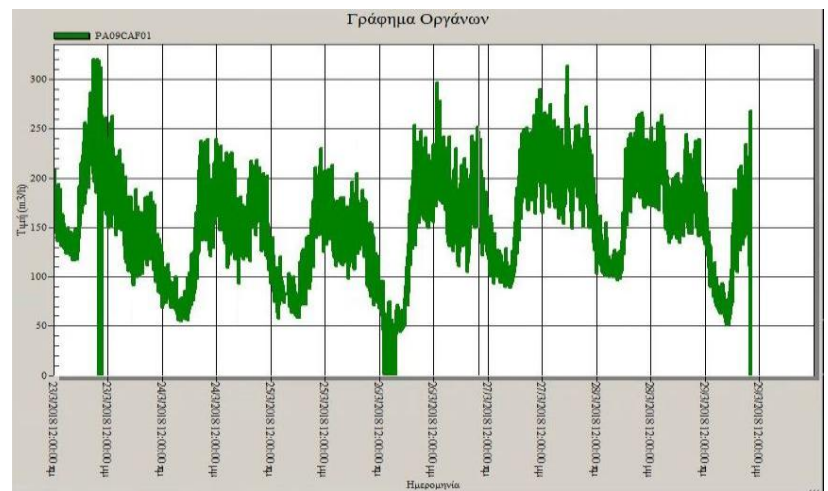

Fig 10: Flowmeter graph, temporal range: this week. [28].

The above graphs come from a tank.

In picture 12.40 , we notice that there are very low water flow values. This results in a corresponding alarm. However, technicians do not immediately leave for the facility. Firstly, they consult the weekly water flow graph.

So we notice that during the week there is another rapid fluctuation in water flow values. There are also other times when water flow is very low and even zero. The fluctuation that triggered the alarm, is thus part of the smooth procession of water flow over time.

Eventually the alarm signal is not due to any real problem in the tank. So, technicians will not need to move toward the installation. This case of possible malfunction, was entirely managed remotely via SCADA. So time was saved, because the technicians did not go to the tank in vain. Resources were saved as well, since every transfer of technicians costs for EYDAP.

SCADA also provides archives of measurement values and facts-incidents.

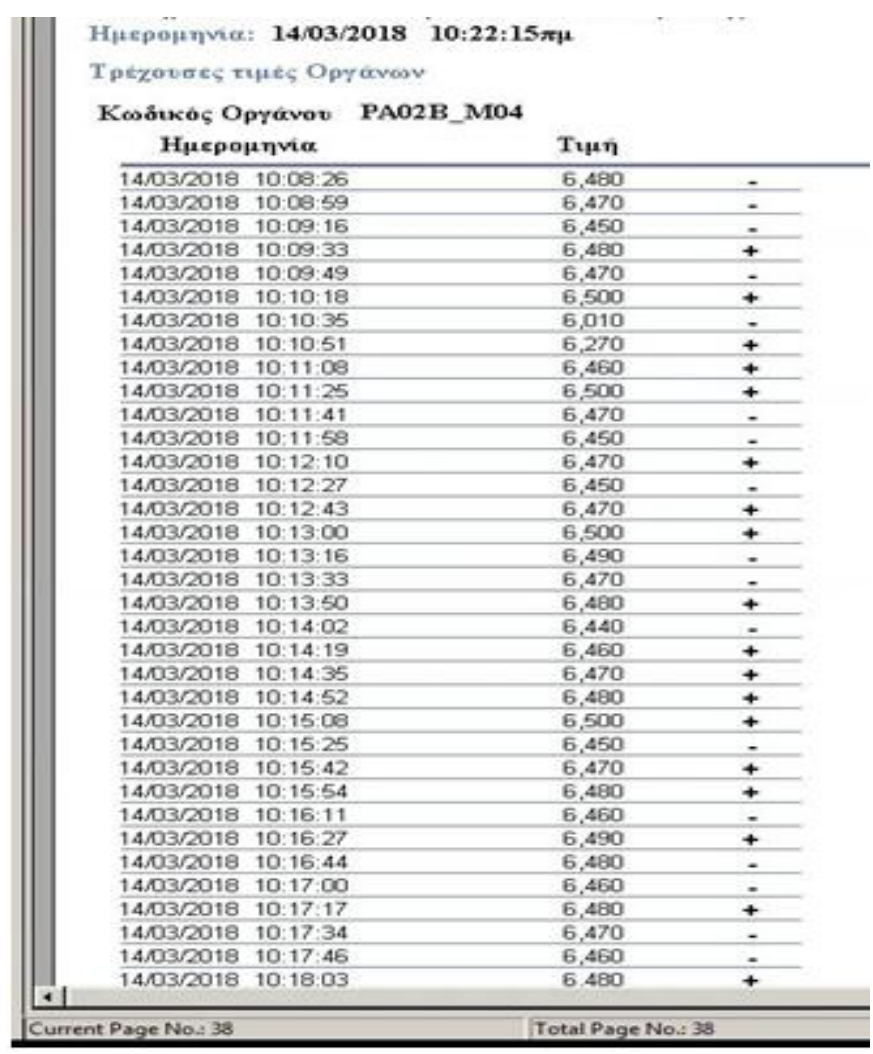

Fig 11: Measurement values of a manometer. [28].

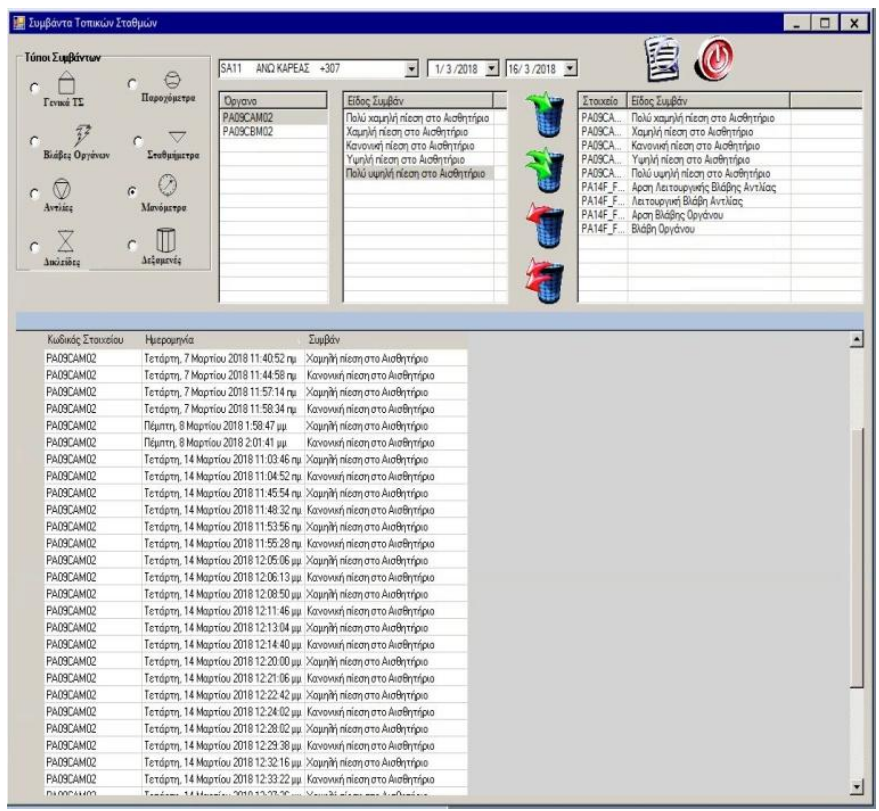

Fig 12: Facts and incidents of local stations. [28].

In picture 12.28 we can see a list of measurement values. This list shows extensively the values of water pressure over time. Accuracy is high as we can see.

In picture 12.27 we can see an archive of facts and incidents. This archive contains a reference for any fact and incident, that has to do with a specific manometer.There is a reference for the sensor's state changes. The sensor's state may change from natural to "low pressure" etc. 
In both of these cases, the time range for which we can get information is too long.

Archives that SCADA provides are very useful to us. With their help, we can draw conclusions about changes or upgrades that the network may need. So we make progress at dealing with the network's problems and preventing the creation of new problems.

\section{CONCLUSIONS}

The main conclusion that we lead after the end of this thesis, concerns the importance and necessity of remote supervising in a water supply network. After reading all of the data and examples set forth in the previous chapters, we can safely arrive at a conclusion. This is that a water supply network could not work so efficiently, if it was not remote supervised via a SCADA system. Remote supervision via SCADA is essential for the effectiveness of technical assistance. It is also essential for having a full picture of the behavior of the entire network and an in-depth understanding of the operation of EM installations. Using SCADA to supervise the water supply network, also provides more time and money for EYDAP.

We also conclude that the proper functioning of a water supply network, requires mixing knowledge from different scientific fields. Such fields are: electrical engineering, mechanical engineering, electronics, automation, IT, telecommunication, topography etc. It is very useful for a technician with any specialization, to gain knowledge from other scientific fields besides the one he is familiar with.

Some conclusions are also drawn regarding the human factor. The main feature that must distinguish all employees in the water supply field is cooperation. In order to avoid problems in the operation of a water supply network, it essential that the people who constitute each department and work at each section should work together flawlessly.

\section{ACKNOWLEDGMENTS}

All authors would like to thank the University of West Attica and specifically the Post Graduate Program of Studies (MSc) "New Technologies in Shipping and Transport", for the financial support provided to them to undertake this research project.

\section{REFERENCES}

[1] https://www.eydap.gr/userfiles/Presentations/etairika_ent ypa/eteriko_2011.pdf, access at 20/2/2018.

[2] Stavroulia Konstantina, <<Management of a water supply network >>, EYDAP-General management of water supply-Management of water supply network, Perissos, 2017.

[3] https://www.eydap.gr/TheCompany/Water/DistributionN etwork/, access at 1/3/2018.
[4] Koutsogiannis D. \& Efstratiadis A., <<Notes of Urban Hydraulic Projects - Water supply projects. Chapter 6: General layout of water supply projects >>, National Technical University of Athens-Field of aqueous resources and environment, Athens, 2015.

[5] Papadakis Vangelis, rapporteur: Syllignakis Ioannis, $<<$ Saving energy using water pumps driven by threephase inductive motors $>>$, TEI of Heraklion- School of Technological Applications - Department of Mechanical Engineering, Heraklion, 2014

[6] Kotsos Panagiotis, rapporteur: Glouftsios Dimitrios, $<$ PUMPS: types, function, set up, maintenance, service, polyrex pump with cogwheels $>>$, TEI of Serres- School of Technological Applications - Department of Mechanical Engineering, Serres, 2008.

[7] EYDAP archive of invitations to tender, Announcement of invitations to tender N. 8182 (https://www.eydap.gr/TheCompany/Contests/NoticesAr chive/). Access at 27/3/2018.

[8] EYDAP archive of invitations to tender, Announcement of invitations to tender N. 8638. (https://www.eydap.gr/TheCompany/Contests/NoticesAr chive/). Access at 27/3/2018.

[9] Kaloidis Eleftherios \& Nikolopoulos Georgios, rapporteur: Schoinas Nikolaos, <<Electrical report of a pumping station $\gg$, TEI of Western Greece-School of Technological Applications -Department of Electrical Engineering, Patra, 2017.

[10] SCADA Interface, of the PC located in Athens's Section RCS.

[11] Veloni Anastasia, $<$ Industrial Informatics. Unit 5: Supervisory Control and Data Collection Systems $>>$, Piraeus University of Applied Sciences-Department of Computer Systems Engineering, Athens, 2015.

[12] Korres Georgios, <<Supervision and Management of Energy Systems-Lectures: Telemetry SystemsSCADA >, National Technical University of Athens School of Electrical \& Computer Engineering, Athens, 2010.

[13] http://www.automatica.gr/, access at 14/12/2018.

[14] Kontozoudis Theodoros, rapporteur: Vradelis Ioannis, $<<$ Expansion and upgrade of telemetry and automation systems at the water supply and sewerage network of Kavala city > , TEI of Kavala- Department of Electrical Engineering, Kavala.

[15] <<Descreiption of open networks used for telecontrol>>, http://www.automatica.gr/, Thessanoliki, 2010. 